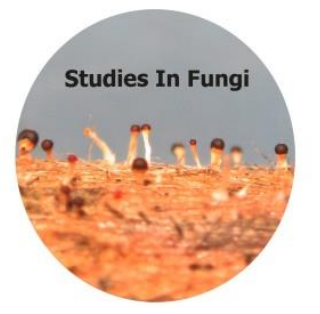

\title{
Article
}

Doi 10.5943/sif/5/1/4

\section{Scleroderma nastii sp. nov., a gasteroid mushroom from Phulchoki hill, Nepal}

\author{
Raut JK ${ }^{1, *}$, Basukala $\mathrm{O}^{1,2}$, Shrestha $\mathbf{R}^{1}$ and Poudel $\mathrm{RC}^{1}$ \\ ${ }^{I}$ Faculty of Science, Nepal Academy of Science \& Technology (NAST), Khumaltar, Lalitpur GPO Box 3323 \\ Kathmandu, Nepal \\ ${ }^{2}$ Current affiliation Tumour Virology Lab, International Centre for Genetic Engineering and Biotechnology (ICGEB), \\ Padriciano 9934149 Trieste, Italy
}

Raut JK, Basukala O, Shrestha R, Poudel RC 2020 - Scleroderma nastii sp. nov., a gasteroid mushroom from Phulchoki hill, Nepal. Studies in Fungi 5(1), 50-58, Doi 10.5943/sif/5/1/4

\begin{abstract}
A new species of Scleroderma is described from temperate Oak forest of Phulchoki hill, at the highest peak $(2,762 \mathrm{~m})$ ringing the Kathmandu valley, Nepal. Smooth to velvety, pseudostipitate basidiome, smaller and sub-reticulate basidiospores in comparison to its close relatives, are key diagnostic features of this newly discovered mushroom. The novelty of the taxon was also confirmed based on phylogenetic analysis using the data sets of the internal transcribed spacer region (ITS) of nuclear rDNA sequences along with the analysis of scanning electron micrographs of its basidiospores. A comprehensive description, illustrations, and comparisons with phenetically similar species are provided in this study. Additional surveys are needed to verify the species diversity and clarify their geographic distribution.
\end{abstract}

Key words - Ectomycorrhiza - Lalitpur - Oak forest - Phylogeny - Pseudostipe

\section{Introduction}

The genus Scleroderma Pers. (Basidiomycota) was described by Persoon in 1801 (Rusevska et al. 2014). It shows a cosmopolitan distribution from temperate to tropical regions forming ectomycorrhizal associations with a wide range of forest trees (Kumla et al. 2013). The Index Fungorum online database (http://www.indexfungorum.org/Names/Names.asp; accessed 07 April 2020) lists 184 Scleroderma species, subspecies, and varieties worldwide. Several species of Scleroderma have been proposed based on morphological characteristics of their basidiomes and basidiospores (Guzmán 1970, Sims et al. 1995, Guzmán et al. 2004, Kumla et al. 2013). Recent studies have also used molecular methods to analyze inter- and intraspecific variation in Scleroderma species (Phosri et al. 2009, Nouhra et al. 2012, Baseia et al. 2016). The characteristics which have been extensively used to separate the species within the genus are the thickness and the scaliness of the peridium and whether the basidiome is stalked or not, and if the former the structure of the stipe. These characteristics at a later date were combined with the size of the basidiospores and their ornamentation and in the latter case whether the ornamentation is composed of isolated spines or warts or forms a reticulum. The spines may be narrow or broadly based or the reticulum complete and very distinctive or incomplete (Phosri et al. 2009). Basidiospore size and pattern of ornamentation were subsequently used by Guzmán (1970), Sims et al. (1995), and Guzmán et al. (2013) to produce identification keys in global basis. Guzmán et al. (2013) divided 
the genus into three sections based on the surface structure of the basidiospores and on the presence or absence of a clamp connection: (1) Reticulatae, characterized by reticulated spores, (2) Scleroderma, with echinulate spores, and (3) Sclerangium, presenting subreticulated spores. Molecular studies, based on comparison of internal transcribed spacer (ITS) nrDNA, confirm this classification (Zhang et al. 2013, Rusevska et al. 2014, Baseia et al. 2016, Crous et al. 2016).

Berkeley (1854, reprint 1969) was first to report six gasteroid fungi including one Scleroderma species ( $S$. nitidum Berk.) from Nepal. Thereafter, altogether nine species, $S$. areolatum Ehrenb (= S. lycoperdoides Schwein), S. bovista Fr., S. cepa Pers. (= S. flavidum Ellis \& Everh.), S. citrinum Pers. (= S. vulgare Horneum), S. polyrhizum (J.F. Gmel.) Pers. (= S. geaster Fr.), S. sinnamariense Mont., S. texense Berk. S. nitidum Berk, and S. verrucosum (Bull.) Pers., have been reported from different parts of the country up to now (Adhikari 2014). During our studies on sequestrate fungi in Kathmandu valley, a new species of Scleroderma was found in Phulchoki hill, the highest peak $(2,762 \mathrm{~m})$ ringing the valley. A complete description, illustration and phylogenetic analysis based on ITS nuclear rDNA along with the scanning electron micrographs analysis of basidiospores of the species are presented here.

\section{Materials and Methods}

\section{Morphology}

Basidiomata were collected from oak forest of Phulchoki hill, Nepal during the rainy season in July 2012. Fresh specimens were examined and photographed. All descriptions of macro- and microscopic features were obtained from fresh as well as dried materials. Microscopic observations and measurements were made on material mounted in $25 \%$ aqueous ammonia. Color terms and notations used in this description are based on Kornerup \& Wanscher (1978). Herbarium abbreviations are according to Holmgren \& Holmgren (1998). Basidiospore statistics: $\mathrm{x}_{\mathrm{m}}$, the arithmetic mean of the spore length by spore width ( \pm standard deviation); n, number of spores measured; Q, the quotient of spore length and width; $\mathrm{Qm}_{\mathrm{m}}$, the mean of Q-values $( \pm$ standard deviation). For scanning electronic microscopy (SEM) of spores, specimens were mounted directly on aluminum stubs with a carbon band and subsequently covered with a layer of gold with $15 \mathrm{~nm}$ in thickness, using a JEOL Smart Coater. Spores were examined in microscope model JEOL - JSM IT100.

\section{DNA extraction}

Fruit body was cut into small pieces and manually grounded in $1.5 \mathrm{~mL}$ microcentrifuge tubes to obtain about $50 \mathrm{mg}$ of dried mushroom. Thereafter $500 \mu \mathrm{l}$ of pre-warmed (at $60^{\circ} \mathrm{C}$ in water bath) TES lysis buffer (100 mM Tris pH 8.0; $10 \mathrm{mM}$ EDTA pH 8.0; 2\% SDS with $10 \mu$ proteinase $\mathrm{K}$ was added and incubated in $60^{\circ} \mathrm{C}$ for $1 \mathrm{hr}$. Then $140 \mu \mathrm{l}$ of $5 \mathrm{M} \mathrm{NaCl}$ and $64 \mu \mathrm{l}$ of $10 \%(\mathrm{w} / \mathrm{v})$ of $\mathrm{CTAB}$ were added to the suspension and incubated at $65^{\circ} \mathrm{C}$ for 10 minutes. The supernatant was taken in new tubes and centrifuged at $14000 \mathrm{rpm}$ for 10 minutes at $4^{\circ} \mathrm{C}$. After centrifugation, equal volume (around $500 \mu \mathrm{l})$ of chloroform:isoamyl alcohol $(24: 1)$ was added and again centrifuged at $14000 \mathrm{rpm}$ for 10 minutes. After that 0.6 volume of cold isopropanol and 0.1 volume of $3 \mathrm{M}$ sodium acetate $\mathrm{pH} 5.2$ were added and maintained overnight at $-20^{\circ} \mathrm{C}$. Next day the mixture was centrifuged at $14000 \mathrm{rpm}$ for 15 minutes at $4^{\circ} \mathrm{C}$ and pellet was obtained throwing the supernatant. The pellet was washed twice with $70 \%$ ethanol and air dried. Then, the obtained DNA pellet was suspended in $100 \mu \mathrm{l}$ of TE with $10 \mathrm{mg} / \mathrm{ml}$ RNase and stored at $-20^{\circ} \mathrm{C}$ for further use. Concentration, yield, and quality control indices based on absorbance readings at 230, 260, and 280 nm (A260/280 and A260/230 ratios) were carried out. Genomic DNA was visualized in 1\% agarose gel.

\section{PCR and Sequencing}

A pair of primers ITS1 (5'-TCCGTAGGTGAACCTGTCGG-3') and ITS4 (5'TCCTCCGCTTATTGTATGC-3') was used to amplify the ITS1-5.8S-ITS4 ribosomal DNA 
region. PCR reaction was performed in $25 \mu 1$ reaction volume, each containing $25 \mathrm{ng}$ of template DNA, $1.5 \mathrm{U}$ Taq-DNA polymerase, $200 \mu \mathrm{M}$ each of dATP, dTTP, dGTP and dCTP, 1X PCR buffer, $2.5 \mathrm{mM} \mathrm{MgCl}_{2}$ (Fermentas, Thermo Fisher Scientific) and $0.4 \mu \mathrm{M}$ of each primer. The reaction mixtures were incubated in Applied Biosystems Veriti 96 well thermal cycler. (Thermo Fisher Scientific, USA) programmed with an initial cycle of $3 \mathrm{~min}$ at $94^{\circ} \mathrm{C}, 1 \mathrm{~min}$ at $50^{\circ} \mathrm{C}$ and 2 min at $72^{\circ} \mathrm{C}$, followed by 39 cycles of $30 \mathrm{~s}$ at $94^{\circ} \mathrm{C}, 30 \mathrm{~s}$ at $50^{\circ} \mathrm{C}$, and $1.15 \mathrm{~min}$ at $72^{\circ} \mathrm{C}$. The final extension cycle consisted of $5 \mathrm{~min}$ at $72^{\circ} \mathrm{C}$ and $2 \mathrm{~min}$ at $25^{\circ} \mathrm{C}$. PCR products were separated via electrophoresis on a $1.5 \%$ agarose gel in $1 \times$ TAE buffer. The bands were stained with ethidium bromide (45 min in 1× TAE buffer) and faded in water for $15 \mathrm{~min}$ prior to visualization and documented using gel documentation system (Syngene Bioimaging, UK). PCR products were purified and sequenced by a dideoxy-mediated chain termination method (Sanger et al. 1977). The sequencing was done in ABI 3500XL genetic analyzer housed at Nepal Academy of Science and Technology, laboratory. Sequence was assembled and edited using the Codoncode Aligner version 4.1 software. The edited sequence was then used for BLAST search in the GenBank database (www.ncbi.nlm.nih.gov). The newly generated nucleotide sequence was deposited in GenBank /EMBL/DDBJ under the accession number KJ740390.

\section{Sequence Divergence and Phylogeny}

Sequence divergence and phylogenetic analysis was performed to know the relationship of newly described taxon with other species of Scleroderma. Nine different species of Scleroderma representing wider geographic regions have been considered to compare with our taxon in the phylogenetic analysis. A total of 33 ITS sequences of varied Scleroderma species from different areas including out group were retrieved from GenBank (Table 1). Pisolithus arhizus was used as an out-group since it is close relative of Scleroderma. Our analysis comprises a set of 34 sequences including out group and our taxon. Sequence matrix of all 34 accessions were aligned using ClustalW in MEGA software version 6 (Tamura et al. 2013) and the resulting alignment was manually adjusted in necessary nucleotide positions. Sequence divergence between Scleroderma species was estimated using Kimura 2 Parameter (K2P) in MEGA. The alignment was deposited in TreeBASE (http://www.treebase.org/) under the accession URL and number http://purl.org/phylo/treebase/phylows/study/TB2:S25819?x-access

code $=$ a01ded $10319 \mathrm{c} 27 \mathrm{~d} 179 \mathrm{bf} 2 \mathrm{~b} 5 \mathrm{e} 4 \mathrm{db} 78 \mathrm{f} 15 \&$ format $=\mathrm{html}$. Maximum parsimony (MP) analysis was performed with the alignment matrix in MEGA 6. All positions containing gaps and missing data were not considered for analyses. The MP tree was obtained using the Tree-BisectionRegrafting (TBR) algorithm (Nei \& Kumar 2000) with search level 1 in which the initial trees were obtained by the random addition of sequences (10 replicates). The robustness of inferred MP tree topologies was tested by the bootstrap value (Felsenstein 1985) with 1000 replicates.

Table 1 List of taxa included in the phylogenetic analyses with their herbarium number, country of origin and GenBank accession numbers of internal transcribed spacer (ITS) nuclear rDNA.

\begin{tabular}{llll}
\hline Taxon & Voucher Specimen No. & Origin & GenBank accession No. \\
\hline S. areolatum & ARESCL2 & USA & FM213352 \\
& ARESCL3 & USA & FM213353 \\
& OSC122632 & USA & FM213351 \\
& OSC38819 & USA & EU819438 \\
& PGK193 & USA & GQ166910 \\
S. bermudense & BZ3961 & Belize & EU718118 \\
S. bovista & N.A. & Japan & AB099901 \\
& N.A. & Japan & AB211267 \\
& MCF 01/168 & Macedonia & HF933234 \\
& MCF 05/788 & Macedonia & HF933235 \\
\hline
\end{tabular}


Table 1 Continued.

\begin{tabular}{|c|c|c|c|}
\hline Taxon & Voucher Specimen No. & Origin & GenBank accession No. \\
\hline & MCF 09/11184 & Serbia & HF933242 \\
\hline \multirow{3}{*}{ S. сера } & SOC-541 & USA & DQ453694 \\
\hline & HE2907 & & KC505548 \\
\hline & CEPSCL5 & USA & FM213355 \\
\hline \multirow[t]{4}{*}{ S. citrinum } & SCL3 & UK & FM213333 \\
\hline & SCL7 & UK & FM213335 \\
\hline & E00278300 & USA & FM213344 \\
\hline & K (M) 53906 & UK & EU784414 \\
\hline S. nastii & NAST-FB11 & Nepal & KJ740390 \\
\hline \multirow[t]{4}{*}{ S. nitidum } & UFRN-Fungos 2034 & Brazil & KU759904 \\
\hline & UFRN-Fungos 2550 & Brazil & KU759906 \\
\hline & UFRN-Fungos 2219 & Brazil & KU759908 \\
\hline & UFRN-Fungos 2500 & Brazil & KU759909 \\
\hline \multirow[t]{2}{*}{ S. polyrhizum } & POLSCL1 & USA & FM213349 \\
\hline & POLSCL2 & USA & FM213350 \\
\hline \multirow[t]{4}{*}{ S. sinnamariense } & SCLK4 & Thailand & FM213356 \\
\hline & SCLP3 & Thailand & FM213357 \\
\hline & SCLY5 & Thailand & FM213359 \\
\hline & $\mathrm{SC} 1$ & Thailand & FM213360 \\
\hline \multirow[t]{4}{*}{ S. verrucosum } & MCF 07/7984 & Macedonia & HF933232 \\
\hline & MCF 08/10124 & Macedonia & HF933233 \\
\hline & MCF 89/4709 & Macedonia & HF933237 \\
\hline & MCF 06/7265 & Macedonia & HF933241 \\
\hline \multicolumn{4}{|l|}{ Outgroup } \\
\hline Pisolithus arhizus & REG-588 & USA & GU187538 \\
\hline
\end{tabular}

N.A.: not available; new species is described in black bold.

\section{Results}

Scleroderma nastii Raut, sp. nov. Fig. 1

MycoBank number: 835277

Etymology - The species name refers to the acronym of the research organization in Nepal where it was described.

Macroscopic characteristics - Basidiome epigeous, depressed globose to subglobose, 10-13 $\mathrm{mm}$ across and 10-20 $\mathrm{mm}$ tall including mycelial base, smooth to velvety, slightly areolate, blackish-brown. Peridium $1 \mathrm{~mm}$ or $<1 \mathrm{~mm}$ thick, pseudostipitate often transversely cracked. Gleba compact, fleshy to dusty, blackish-brown (Fig. 1a).

Microscopic characteristics - Basidiospores (7-) 8-9 $(-10) \mu \mathrm{m}$ without spines; average $=8.3$, $\mathrm{SD}= \pm 0.7, \mathrm{n}=25$, globose, yellowish brown, subreticulated under LM (Fig. 1b), irregular reticulum under SEM (Fig. 1c)). Basidia not observed. Clamp connections absent

Habit and Habitat- Solitary to caespitose on soil under leaves and litter of Quercus trees in north facing temperate forest.

Known distribution - Only known from the type locality in Nepal.

Material examined - Nepal, Lalitpur, Oak forest in Phulchoki hill, on soil, alt. $2630 \mathrm{~m}$, N27³4.205" E085²4.077", 13 July 2012, J. K. Raut, NAST-FB11 (KATH-FB11, Holotype)

Additional specimen examined - Mexico, Chiapas: near Ocozocuautla, Laguna Bélgica Ecological Park, tropical rain forest, 850 m alt., Oct. 12, 1992, E. Palacios \& T. Cabrera 2112, S. mexicana (holotype, XAL) 




Fig. 1 - Macro- and micro features of Scleroderma nastii (holotype) a Basidiomes with opening gleba. b Basidiospores under light microscope (LM). c Basidiospores under scanning electron microscope (SEM). Scale Bars: $\mathrm{a}=10 \mathrm{~mm}, \mathrm{~b}=20 \mu \mathrm{m}, \mathrm{c}=5 \mu \mathrm{m}$.

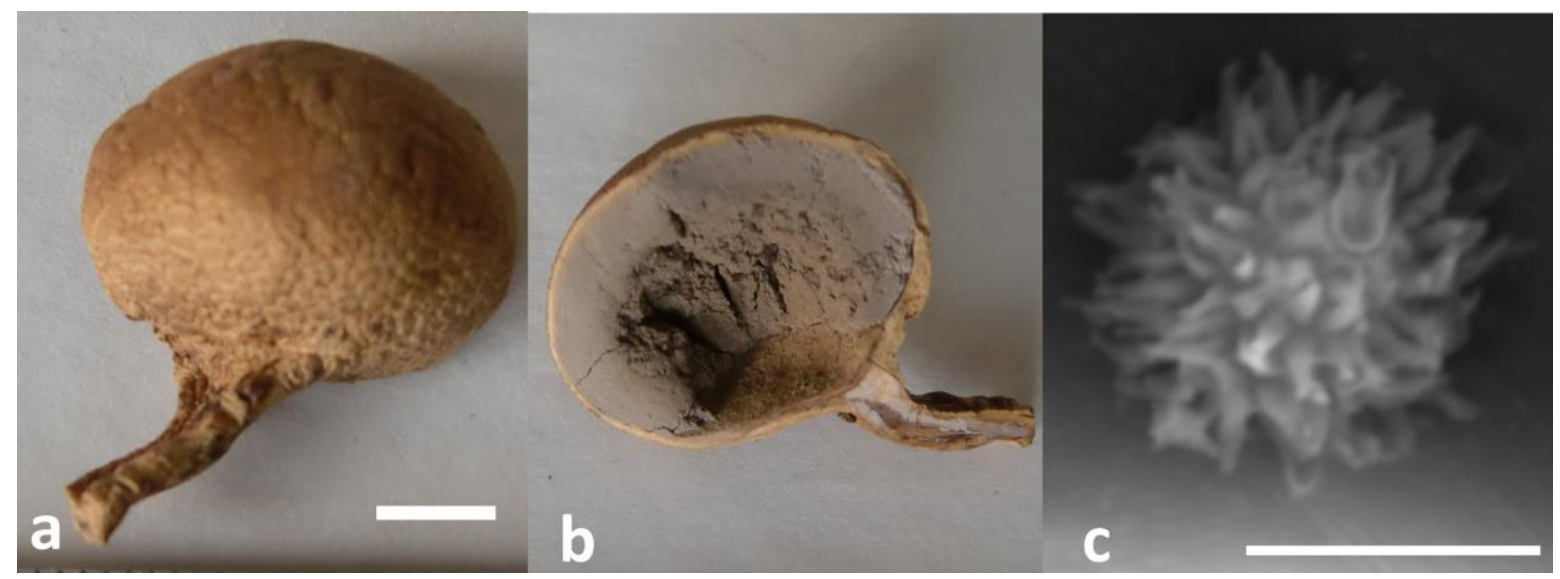

Fig. 2 - Scleroderma mexicana (holotype) a Basidiome. b Basidiome with opening gleba. c Basidiospores under scanning electron microscope (SEM), Scale Bars: $a, b=5 \mathrm{~mm}, \mathrm{c}=5 \mu \mathrm{m}$. 


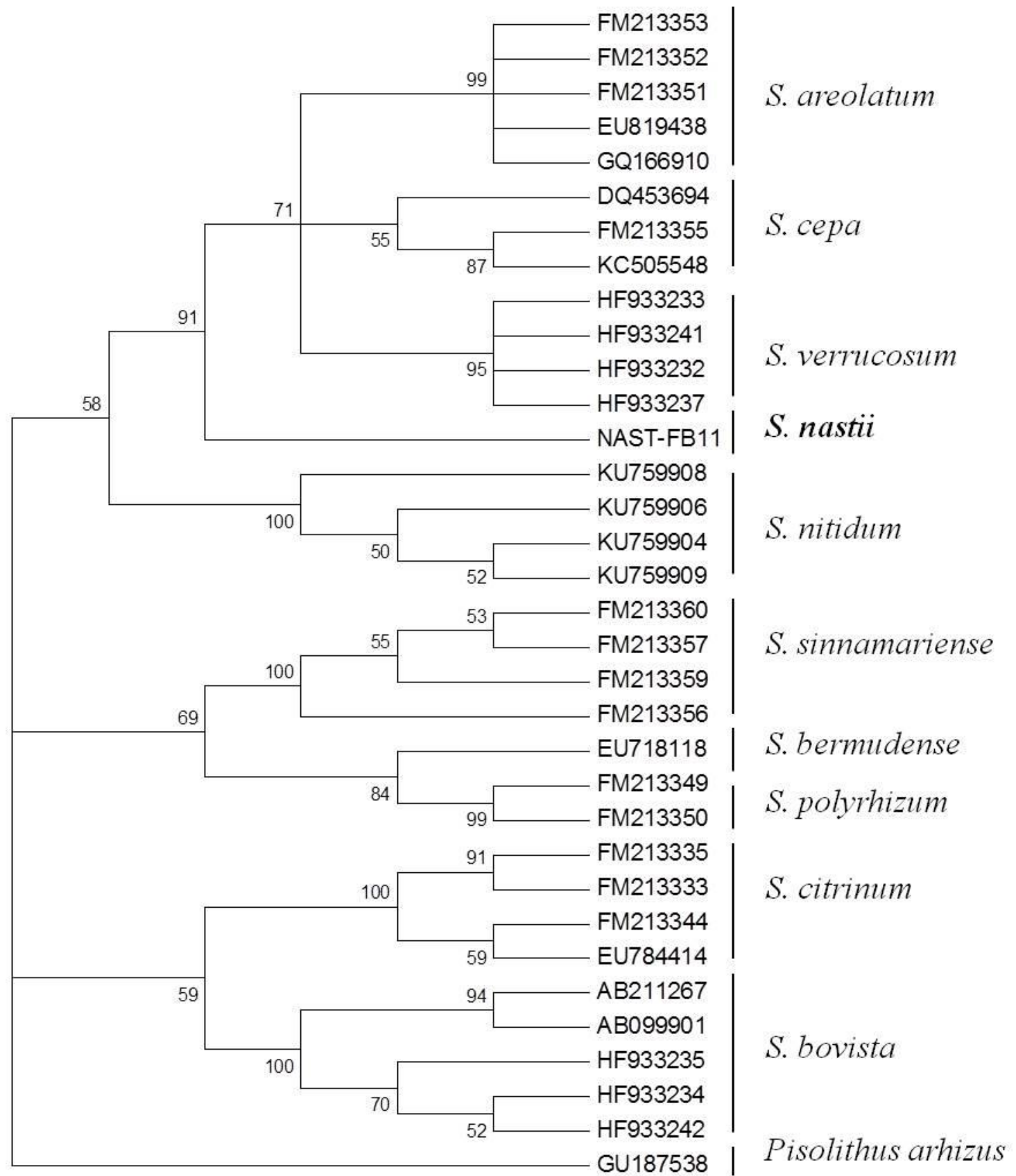

Fig. 3 - Bootstrap consensus tree inferred from 1000 replicates using the Maximum Parsimony method. Numbers on the branches represent bootstrap values. Branches corresponding to partitions reproduced in less than $50 \%$ bootstrap replicates were collapsed. Sidebar represents the inferred clades of Scleroderma species. Pisolithus arhizus was included as out group.

\section{Species delimitation and phylogeny}

Among 33 accessions, the length of the entire ITS region for newly described species, is 676 base pairs. Within the aligned matrix of ITS sequences (including ITS1, 5.8S and ITS4), our species had six unique mutations. Sequence divergence between species based on Kimura 2 Parameter revealed that Scleroderma congeners maintained a range of species divergence from $3.08-13.60 \%$. The lowest species divergence was between $3.08-3.94 \%$ in S. areolatum, S. cepa and $S$. verrucosum group. The highest species divergence was between 10.70-13.60\% in rest of the other groups ( $S$. sinnamariense, S. bermudense, S. polyrhizum, S. citrinum and S. bovista) except $S$. nitidum, to which divergence was $8.09 \%$. 
The Maximum Parsimony analysis of the dataset results 8 Parsimonious trees with a length of 248 steps. MP inferred a consistency index $(\mathrm{CI})=0.7439$, a retention index $(\mathrm{RI})=0.922$ and a composite index of 0.640927 . In total three moderately supported clades with bootstrap values $>58$ $\%$ were observed. The first clade with bootstrap support value of $69 \%$ was contained with $S$. sinnamariense, S. bermudense, and S. polyrhizum. The second clade consists S. citrinum and $S$. bovista with bootstrap support value of 59\%. Newly described species $S$. nastii was clustered in the third clade with $S$. areolatum, $S$. cepa, $S$ verrucosum and $S$. nitidum. Within the third clade, $S$. nastii, as shown in the strict consensus tree (Fig. 3), forms strong relation with $S$. nitidum and $S$. areolatum, S. cepa and S. verrucosum grouped with very strong bootstrap value of $>90 \%$.

\section{Discussion}

Morphologically Scleroderma nastii is very close to $S$. verrucosum, $S$. areolatum, S. cepa, $S$. mexicana, and $S$. nitidum especially in the terms of basidiospores size and stipe. However, it differs from all those by its irregular reticulum spore ornamentation (Table 2). Additionally, it differs from $S$. verrucosum, $S$. areolatum by their verrucose scaly exoperidium and comparatively larger basidiome. Scleroderma areolatum is close to $S$. verrucosum; only the size of the basidiospores separates both species and the exoperidium is covered with numerous tiny patches or scales, which in $S$. areolatum are surrounded by a ring zone, giving an areolate structure. Likewise the stipe in $S$. nastii (Fig. 1) is not well formed like in S. mexicana (Fig. 2) which is sharply stipitate and reported only from type locality in tropical region with spiny spore ornamentation.

Scleroderma nitidum had been interpreted in different ways since it was described by Berkeley (1854) from Nepal. It was considered as an independent taxon by Guzmán in 1967 and later it was synonymized with $S$. verrucosum (Guzmán 1970). Guzmán \& Tapia (1995) considered S. nitidum as Veligaster nitidus, due to a well-developed solid stipe, with darker subgelatinous patches in the upper part, as well as in the base of the globose part of the basidiome which are the typical features of Veligaster. After the synonymy of Veligaster with Scleroderma, V. nitidus was synonymized with $S$. nitidum (Guzmán et. al. 2013). The type of $S$. nitidum deposited at Royal Botanic Gardens, Kew has sessile and stipitate basidiomata with (8- ) 9-11(-13) $\mu \mathrm{m}$ diam. which was collected from eastern Nepal, at 3000 m elevation. Guzmán \& Ramírez-Guillén (2010) studied this species with basidiospores (7- ) 8-11 (-12) diam. in the Guzmán collection which was from Quercus forest in a subtropical region of Nepal at 1000 m elevation.

Moreover, in the sequence divergence estimation and phylogenetic analysis based on ITS nucleotide sequences, $S$. nastii formed a conspicuous and distinct clade among its allies. The tree topology is strongly supported by high bootstrap values (Fig. 3), that indicates $S$. nastii is a distinct taxon. This result was observed in another phylogenetic studies of Scleroderma by Baseia et al. (2016) and Crous et al. (2016) as well.

Regarding the ethnomycological importance, S. cepa, S. citrinum, S. sinnamariense, S. texense and $S$. verrucosum are reported as edible in Nepal. They are sold in local markets and consumed even as raw by local Tamang ethnic group. They are locally known as various names such as Aalu Chyau, Dalle Chyau, Til Chyau, Paduke Chyau, Kudaki Chyau, Bhudkee Chyau, Patteu Chyau and Shankan Shyamo in the different parts of Nepal (Christensen et al. 2008, Adhikari 2014). However, no any ethnomycological information about this newly discovered Scleroderma was recorded during the study.

Table 2 Distinguishing features of $S$. nastii with other close relatives in the genus.

\begin{tabular}{|c|c|c|c|c|c|}
\hline & $\begin{array}{l}\text { Spore size } \\
(\mu \mathrm{m})\end{array}$ & Ornamentation & Eco-region & Basidome & Reference \\
\hline $\begin{array}{l}S . \\
\text { areolatum }\end{array}$ & $\begin{array}{l}(9-) 10-15(- \\
18)\end{array}$ & Spiny & Temperate & $\begin{array}{l}\text { 15-30 mm diam, dark } \\
\text { brown or blackish } \\
\text { scales, sessile or } \\
\text { shortly } \\
\text { pseudostipitate }\end{array}$ & $\begin{array}{l}\text { Guzmán et al. } \\
2013\end{array}$ \\
\hline
\end{tabular}


Table 2 Continued.

\begin{tabular}{|c|c|c|c|c|c|}
\hline & $\begin{array}{l}\text { Spore size } \\
(\mu \mathrm{m})\end{array}$ & Ornamentation & Eco-region & Basidome & Reference \\
\hline S. сера & $\begin{array}{l}\text { (7-) 8-13(- } \\
14)\end{array}$ & Spiny & Temperate & $\begin{array}{l}20-30(-40) \mathrm{mm}, \\
\text { smooth to coarsely } \\
\text { cracked, sessile }\end{array}$ & Guzmán et al. 2013 \\
\hline S. mexicana & $\begin{array}{l}\text { (7-) 8-10 (- } \\
11)\end{array}$ & Spiny & Tropical & $\begin{array}{l}10-26 \mathrm{~mm} \text { diam., } \\
\text { smooth to somewhat } \\
\text { velvety, stipitate }\end{array}$ & Guzmán et al. 2013 \\
\hline S. nastii & $(7-) 8-9(-10)$ & $\begin{array}{l}\text { Irregular } \\
\text { reticulum }\end{array}$ & Temperate & $\begin{array}{l}10-13 \mathrm{~mm} \text { across, } \\
\text { smooth to somewhat } \\
\text { velvety, } \\
\text { pseudostipitate }\end{array}$ & Present work \\
\hline S. nitidum & $\begin{array}{l}(7-) 8^{8-11(-} \\
12)\end{array}$ & Spiny & $\begin{array}{l}\text { Tropical or } \\
\text { Subtropical }\end{array}$ & $\begin{array}{l}(15-) 20-25(-30) \\
\text { mm diam., verrucose- } \\
\text { scaly, sessile or } \\
\text { sharply stipitate }\end{array}$ & Guzmán et al. 2013 \\
\hline $\begin{array}{l}S . \\
\text { verrucosum }\end{array}$ & $\begin{array}{l}(8-) \text { 9-12(- } \\
14)\end{array}$ & Spiny & $\begin{array}{l}\text { Temperate } \\
\text { or } \\
\text { Subtropical }\end{array}$ & $\begin{array}{l}(20-) 25-30(-45) \\
\text { mm diam., small dark } \\
\text { brown or blackish } \\
\text { scales, shortly } \\
\text { pseudostipitate }\end{array}$ & Guzmán et al. 2013 \\
\hline
\end{tabular}

\section{Acknowledgements}

Authors are very thankful to Nepal Academy of Science \& Technology (NAST) for providing all kinds of support to conduct this work. The members of Molecular Biotechnology Unit, are greatly acknowledged for their kind cooperation in the molecular work. For the scanning electron microscopy, Plant pathology division, NARC is also greatly acknowledged. The authors are also deeply indebted to Dr. Gastón Guzmán, Emeritus Research and Curator of the Fungus Collection of Instituto de Ecología Xalapa, Mexico for making available herbarium specimen of Scleroderma maxicana (holotype) and some relevant and important reprints of his work.

\section{References}

Adhikari MK. 2014 - Mushrooms of Nepal. (Eds by G. Durrieu, \& H.V.T. Cotter) Published by KS Adhikari, Kathmandu, Nepal. pp. 340.

Baseia IG, Silva BDB, Ishikawa NK, Soares JVC et al. 2016 - Discovery or Extinction of New Scleroderma Species in Amazonia? Plos One 11(12), 1-19.

Berkeley MJ. 1854 - Decades of fungi XLI-XLVI. Indian fungi. Hooker Journal of Botany \& Kew Miscellaneous Papers 6: 129-143 + pls. 3-8, \& 161-174. Reprinted 1969 by Donk, M.A., Decades of fungi, Decas 1-62, Asher, Amsterdam.

Christensen M, Bhattarai S, Devkota S, Larsen HO. 2008 - Collection and Use of Wild Edible Fungi in Nepal. Economic Botany 62(1), 12-23.

Crous PW, Wingfield MJ, Richardson DM, Leroux JJ et al. 2016 - Fungal Planet description sheet:447. Persoonia. 36, 412-413.

Felsenstein J. 1985 - Confidence limits on phylogenies: an approach using bootstrap. Evolution 39, 783-791.

Guzmán G. 1967 - Taxonomía del género Scleroderma Pers. emend. Fr. Ciencia (Méx.) 2, 195208.

Guzmán G. 1970 - Monografía del género Scleroderma Pers. emend. Fr. (Fungi-Basidiomycetes). Darwiniana 16, 233-401. 
Guzmán G, Cortés-Pérez1 A, Guzmán-Dávalos L, Ramírez-Guillén F, Sánchez-Jácome M. 2013 An emendation of Scleroderma, new records, and review of the known species in Mexico. Revista Mexicana de Biodiversidad, S173-S191, DOI: 10.7550/rmb.31979.

Guzmán G, Ramírez-Guillén F. 2010 - An overview on some mushroom from Nepal. Boletín de la Sociedad Micológica de Madrid 34, 295-320.

Guzmán G, Ramirez-Guillém F, Miller OK, Lodge DJ. 2004 - Scleroderma stellatum versus Scleroderma bermudense: the status of Scleroderma echinatum and the first record of Veligaster nitidum from the Virgin Islands. Mycologia 96, 1370-1379.

Guzmán G, Tapia F. 1995 - New species, new combinations and new records of Veligaster (Sclerodermataceae). Documents Mycologiques. 25(98-100), 185-195.

Holmgren PK, Holmgren NH. 1998 - Index Herbariorum: A global directory of public herbaria and associated staff. New York Botanical Garden's Virtual Herbarium. http://sciweb.nybg.org/science2/indexHerbariorum.asp.

Kornerup A, Wanscher JH. 1978 - Methuen Handbook of Color, 3rd edn. Sankt Jorgen Tryk Ltd, Copenhagen.

Kumla J, Suwannarach N, Bussaban B, Lumyong S. 2013 - Scleroderma suthepense, a new ectomycorrhizal fungus from Thailand. Mycotaxon 123, 1-7.

Nei M, Kumar S. 2000 - Molecular Evolution and Phylogenetics. Oxford University Press, New York.

Nouhra ER, Caffot MLH, Pastor N, Crespo EM. 2012 - The species of Scleroderma from Argentina, including a new species from the Nothofagus forest. Mycologia 104, 488-495. http://dx.doi.org/10.3852/11-082.

Phosri C, Martin MP, Watling R, Jeppson M, Sihanonth P. 2009 - Molecular phylogeny and reassessment of some Scleroderma spp. (Gasteromycetes). Anales del Jardín Botánico de Madrid 166, 83-91.

Rusevska K, Karadelev M, Phosri C, Dueñas M et al. 2014 - Rechecking of the genus Scleroderma (Gasteromycetes) from Macedonia using barcoding approach. Turkish Journal of Botany 38, 375-385.

Sanger F, Nicklen S, Coulson AR. 1977 - DNA sequencing with chain-terminating inhibitors. Proceedings of the National Academy of Sciences, USA 74, 5463-5467.

Sims KP, Watling R, Jeffries P. 1995 - A revised key to the genus Scleroderma. Mycotaxon 51, 403-420.

Tamura K, Stecher G, Peterson D, Filipski A, Kumar S. 2013 - MEGA6: Molecular Evolutionary Genetics Analysis version 6.0. Molecular Biology and Evolution 30, 2725-2729.

Zhang C, Xu X, Liu J, He M et al. 2013 - Scleroderma yunnanense, a new species from South China. Mycotaxon 125, 193-200. 